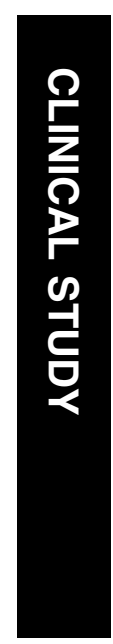

\title{
UK national survey of current practice and experience of intravitreal triamcinolone acetonide
}

${ }^{1}$ Department of Ophthalmology, Leicester Royal Infirmary, Leicester, UK

${ }^{2}$ Academic Unit of Respiratory Medicine, Department of Medicine, Royal Free and University College Medical School, London, UK

${ }^{3}$ Department of Epidemiology, University of Leicester, Leicester, UK

${ }^{4}$ Department of Ophthalmology, Norfolk and Norwich University Hospital, Colney Lane, Norwich, UK

Correspondence: S Jain, Department of Ophthalmology, Leicester Royal Infirmary, Infirmary Square, Leicester LE1 5WW, UK Tel: +0116 254 1414; Fax: + 01162585927 . E-mail: saurabh.uk@ gmail.com

Received: 29 February 2008 Accepted in revised form: 22 May 2008 Published online: 13 June 2008

\section{Abstract}

Aims In recent years, intravitreal triamcinolone acetonide (IVTA) injections have become widely used in the treatment of macular oedema. IVTA can cause elevation of intraocular pressure (IOP), which can be sight threatening. We carried out a nationwide study, which aimed to (i) assess the current usage of IVTA, (ii) estimate the incidence of 'severe' IOP rise following IVTA, in routine practice.

Methods A postal survey was carried out in January 2007. A questionnaire was mailed to senior ophthalmologists (all consultants and associate specialists) in the United Kingdom. We asked about the use of IVTA over the past year and whether there had been any cases of severe IOP rise (defined as elevation in IOP, commencing after IVTA therapy, requiring laser or surgery to treat the raised pressure). Results Response rate was 56\% (611/1089). Among respondents, 33\% (206) had used IVTA during the 12 months of 2006 giving a total of 3899 IVTA injections. There were 45 reported cases of severe IOP rise, following IVTA injections, which were given under their care of the respondent. A further 28 cases were reported to have been referred from colleagues; it is unclear whether any or all of these cases were included in the initial 45 . The reported rate of severe IOP rise following IVTA was therefore at least $45 / 3899$ or at least $1.1 \%$. Conclusions Usage of IVTA in the United Kingdom is widespread. Severe IOP rise, requiring laser or surgery to control IOP, was reported in at least $1.1 \%$ of cases.

Eye (2009) 23, 1164-1167; doi:10.1038/eye.2008.185; published online 13 June 2008

Keywords: side effects; intravitreal; triamcinolone; glaucoma
S Jain ${ }^{1}$, J R Hurst ${ }^{2}$, JR Thompson ${ }^{3}$ and T Eke ${ }^{4}$

Introduction

Intravitreal triamcinolone acetonide (IVTA) injections are used for a variety of indications in ophthalmology. IVTA has been used in the treatment of macular oedema following cataract surgery, vascular occlusions, diabetic

retinopathy, macular degeneration, intraocular inflammation, and juxtafoveal telengiectasis. ${ }^{1,2}$ The mechanism by which intravitreal steroids cause a reduction in macular oedema remains unclear but they have been shown to stabilise the blood retinal barrier and reduce vitreous concentration of vascular endothelial growth factor (VEGF). ${ }^{3-5}$

IVTA has been shown to cause uveitis, cataracts, secondary endophthalmitis, and raised intraocular pressure (IOP). ${ }^{3}$ This secondary rise in IOP, may be immediate or late and is transient in most cases. However, the IOP rise can be sight threatening, if it remains persistently and significantly elevated, especially in those with preexisting glaucomatous optic nerve damage. Moreover, the risk of IOP rise may be greater with repeated injections. ${ }^{2,6}$ Patients with a prior diagnosis of glaucoma are thought to be at higher risk of having a significant IOP rise, ${ }^{7,8}$ so these patients have been excluded from some prospective studies of IVTA outcomes and complications. ${ }^{9}$ As far as we are aware, the incidence of significant post-IVTA IOP rise in routine clinical practice has not been addressed in any large study.

A recent editorial has proposed a classification system for post-IVTA IOP rise. ${ }^{10}$

A rise of $\geqslant 15 \mathrm{mmHg}$ from baseline or an IOP consistently higher than $32 \mathrm{mmHg}$ would be classified as a 'mild adverse event'. If the IOP elevation does not respond adequately to topical therapy or persists beyond three months, 
this would be a 'moderate adverse event'. A 'severe adverse event' would be a rise in pressure to such a level that surgery or laser is necessary.

We have carried out a nationwide survey to study the current usage of IVTA and the incidence of severe IOP rise following IVTA. For the purposes of the study, we defined a 'severe' IOP rise following IVTA as an elevation in IOP, attributable to IVTA therapy, requiring laser or surgery to treat the raised pressure.

\section{Methods}

We carried out a nationwide postal survey of all senior ophthalmologists (consultant and associate specialist grade) in the United Kingdom. In January 2007, we mailed questionnaires to all 1089 names on a database held by the British Ophthalmic Survey Unit (BOSU). The mailing comprised a two-page questionnaire with a covering letter and a stamped addressed envelope for return.

Ophthalmologists were asked a series of questions about their personal use and experience of IVTA over the previous 12 months (January-December 2006). We asked the grade and specialty of the respondent, the total number of patients treated in 2006, the indications for treatment, and whether there was a departmental policy (written or unwritten) regarding the use of IVTA. Respondents were also asked to record any cases of severe IOP rise following IVTA given to patients under their care and also to report any cases that they had managed, following IVTA under the care of a colleague. For the purposes of this study, we defined a severe IOP rise as one that was treated with surgery and/or laser to lower the IOP.

The completed questionnaires were returned to the lead investigator and the responses were manually entered into a customised database for analysis.

\section{Results}

\section{Questionnaire return}

We had received 611 completed responses out of 1089 sent (56\% response rate) along with four unopened questionnaires. Of the respondents who indicated their subspecialty or area of interest, 54 were glaucoma specialists $(9 \%)$ and 72 were medical retina specialists (12\%). Fifty-five of the $206(26.7 \%)$ who used IVTA in 2006 were medical retina specialists according to the data collected. It is difficult to draw firm conclusions as some respondents did not indicate their specialty interest but it certainly seems that IVTA use is not restricted to the retina specialists.

\section{Use of IVTA in the United Kingdom}

Exactly one-third of respondents (206/611, 33.3\%) had performed IVTA during 2006. The total number of procedures performed in 2006 by our respondents was reported to be 3899 . Assuming our respondents to be a representative population of the UK ophthalmologists this extrapolates to around 7000 IVTA injections in the United Kingdom in the year 2006.

\section{Indications for IVTA}

Data on the indications for treatment were available from 199 of the 206 respondents who had used IVTA. The commonest cited indications for IVTA by our respondents included diabetic maculopathy (64\% of respondents) and cystoid macular oedema (47\%), for example, following cataract surgery. The other indications included age-related macular degeneration (26.6\%), inflammatory eye disease $(42.5 \%)$, vascular occlusions $(43 \%)$, and other conditions (10.6\%) including following posterior capsule rupture in cataract surgery, during paediatric cataract surgery, after choroidal resection of melanoma, during epiretinal membrane peel or pars plana vitrectomy, and for neovascular glaucoma.

\section{Complications of IVTA}

Forty-five cases of severe IOP rise (requiring laser or surgery) were reported to have occurred after an initial IVTA injection that was performed under the care of the respondent. These 45 cases were reported by 28 respondents. A further 28 cases of severe IOP rise were reported to have occurred after IVTA injection by another ophthalmologist; it is unclear how many of these 28 cases are included in the initial 45 .

The reported rate of severe IOP rise (requiring laser or surgery) following IVTA was therefore at least 45/3899 $(1.1 \%)$, and possibly as high as $73 / 3899(1.9 \%)$.

Data on previous glaucoma status were available for nine of these patients: glaucoma (1), pseudoexfoliative glaucoma (1), previous steroid response (1), ocular hypertension (1), and no previous glaucoma (5).

\section{Guidelines for IVTA use}

In 2006, few ophthalmology departments had guidelines for the use of IVTA in glaucomatous eyes. Only $2.2 \%$ of our respondents had a departmental written policy relating to intravitreal injections. A total of $11.9 \%$ of respondents said that they avoided IVTA in glaucomatous eyes. 


\section{Discussion}

The use of IVTA is widespread among the UK ophthalmologists, with at least 3899 and possibly up to 7000 IVTA injections performed in 2006. Our survey found the incidence of severe IOP rise (surgery or laser to reduce IOP after IVTA) was at least $1.1 \%$. The use of IVTA appears to be increasing. A study survey conducted in November 2004, also looking at ophthalmologists on the BOSU database, found that $24.7 \%$ of respondents used IVTA regularly, while a third $(33.3 \%)$ of our respondents used IVTA in 2006 accounting for a total of 3899 procedures. ${ }^{11}$

The frequency of IOP rise after IVTA in glaucomatous and non-glaucomatous eyes has been reported in several studies. For studies that did not exclude patients with a glaucoma diagnosis, the incidence IOP rise after IVTA ranged from $28-77 \%,{ }^{7-8,12-17}$ though study methods and IOP criteria varied widely. Incidence of severe IOP rise (requiring surgery or laser) has been reported as 1/130 $(0.9 \%),{ }^{3}$ and $5 / 570(0.1 \%)$ for single injections and for repeat injections, the rate was $1 / 43(2.3 \%),{ }^{2} 3 / 305$ $(1 \%)^{7}$ and $1 / 93(1.1 \%) .{ }^{17}$ In this study, we calculated the risk of severe IOP rise after IVTA to be at least $1.1 \%$.

The risk factors for predicting IOP rise after IVTA have also been studied. These include a baseline IOP $>15 \mathrm{mmHg}$, younger age, repeated injections (due to the cumulative effect), and a positive provocative test (with a $400 \mu \mathrm{g}$ dose). Studies indicate no demonstrable effect of age, sex, diagnosis, refractive error, or preexisting diabetes. ${ }^{18-20}$ There is currently no data on the rate of success and postoperative course of post IVTA trabeculectomies.

The relationship between severe IOP rise after IVTA and preexisting glaucoma has still not been established, though several small studies have suggested a link. Bakri and Beer observed transient IOP elevation in two of six eyes $(33.3 \%$ ) with preexisting glaucoma in a series of 43 eyes of 38 patients receiving IVTA. In all these cases, the IOP settled on topical medication within 12 weeks of the injection. $^{10}$

Giving a small test dose of $400 \mathrm{mg}$ of IVTA provoked an elevated IOP at 1 week in 8-15\% of non-glaucomatous eyes and $33 \%$ of eyes with preexisting glaucoma, indicating that glaucomatous eyes may be at higher risk of severe IOP rise. ${ }^{6}$

One large case series looked at 570 consecutive eyes of 536 patients who received a single IVTA injection $(4 \mathrm{mg} /$ $0.1 \mathrm{ml}$ ) and a second set of 43 eyes of 40 patients who received a second injection. Of these, preexisting glaucoma was present in 97 eyes or $15.8 \%$. Of these, 90 eyes received a single injection and seven eyes received more than one. The investigators concluded that glaucoma status did not predict an IOP elevation in either of these groups in a univariate or multivariate analyses. $^{2}$

It is likely that many patients who may benefit from IVTA are being denied the treatment because of an assumed higher risk of IOP rise after the injection due to preexisting glaucoma or ocular hypertension. Our study points to a positive correlation between an initial diagnosis of glaucoma and significant post IVTA IOP rise, but it is difficult to make conclusive recommendations based on the evidence available at present.

This study has several limitations. The most important ones, being its retrospective nature, are incomplete responses and the inability to obtain further details on cases that had developed severe glaucoma. There is also the possibility of a positive bias among those who replied leading to a falsely elevated estimates of IVTA usage and complications. There is also a possibility of underestimation due to poor recall by respondents, lack of response by those not practicing IVTA, and loss of continual follow-up through referral.

To address these shortcomings, there is the need for a prospective study of severe IOP rise following IVTA. We will shortly be undertaking such a survey, using active surveillance through the BOSU card-reporting system ${ }^{21}$ for case ascertainment. This new study will aim to estimate the incidence of severe IOP rise following IVT, ascertain the characteristics of those patients/eyes that have the severe IOP rise following IVT and look at treatment outcomes at the end of 1 year.

In summary, we have demonstrated that IVTA in the United Kingdom is widespread. In routine practice, the overall incidence of severe IOP rise (requiring laser or surgery) appears to be at least $1.1 \%$, with evidence to suggest that patients with a preexisting glaucoma diagnosis may be more at risk of developing this complication. The forthcoming BOSU study should help to address many outstanding issues.

\section{Acknowledgements}

This study was supported by a bursary from the British Ophthalmic Surveillance Unit.

\section{References}

1 Jonas JB, Kreissig I, Degenring R. Intravitreal triamcinolone acetonide for treatment of intraocular proliferative, exudative, and neovascular diseases. Prog Retin Eye Res 2005; 24: 587-611.

2 Rhee DJ, Peck RE, Belmont J, Martidis A, Liu M, Chang J et al. Intraocular pressure alterations following intravitreal triamcinolone acetonide. Br J Ophthalmol 2006; 90: 999-1003. 
3 Konstantopoulos A, Williams CP, Newsom RS, Luff AJ. Ocular morbidity associated with intravitreal triamcinolone acetonide. Eye 2007; 21: 317-320.

4 Brooks Jr HL, Caballero Jr S, Newell CK, Steinmetz RL, Watson D, Segal MS et al. Vitreous levels of vascular endothelial growth factor and stromal-derived factor 1 in patients with diabetic retinopathy and cystoid macular edema before and after intraocular injection of triamcinolone. Arch Ophthalmol 2004; 122: 1801-1807.

5 Wilson CA, Berkowitz BA, Sato Y, Ando N, Handa JT, de Juan Jr E. Treatment with intravitreal steroid reduces blood-retinal barrier breakdown due to retinal photocoagulation. Arch Ophthalmol 1992; 110: 1155-1159.

6 Conway MD. The problem of pressure elevation associated with intravitreal triamcinolone. $\mathrm{Br} J$ Ophthalmol 2006; 90: 934-935.

7 Jonas JB, Degenring RF, Kreissig I, Akkoyun I, Kamppeter BA. Intraocular pressure elevation after intravitreal triamcinolone acetonide injection. Ophthalmology 2005; 112: 593-598.

8 Smithen LM, Ober MD, Maranan L, Spaide RF. Intravitreal triamcinolone acetonide and intraocular pressure. Am J Ophthalmol 2004; 138: 740-743.

9 National Eye Institute Clinical Studies Database: (http:// www.nei.nih.gov/neitrials/viewStudyWeb.aspx?id =99). Accessed on 3/9/2006.

10 Jampol LM, Yannuzzi LA, Weinreb RN. Glaucoma and intravitreal steroids. Ophthalmology 2005; 112: 1325-1326.

11 Anijeet DR, Hanson RJ, Bhagey J, Bates RA. National survey of the technique of intravitreal triamcinolone injection in the United Kingdom. Eye 2007; 21: 480-486.
12 Bakri SJ, Beer PM. The effect of intravitreal triamcinolone acetonide on intraocular pressure. Ophthalmic Surg Lasers Imaging 2003; 34(5): 386-390.

13 Jonas JB, Kreissig I, Degenring R. Intraocular pressure after intravitreal injection of triamcinolone acetonide. $\mathrm{Br} J$ Ophthalmol 2003; 87: 24-27.

14 Gillies MC, Simpson JM, Billson FA, Luo W, Penfold P, Chua $\mathrm{W}$ et al. Safety of an intravitreal injection of triamcinolone: results from a randomized clinical trial. Arch Ophthalmol 2004; 122: 336-340.

15 Kaushik S, Gupta V, Gupta A, Dogra MR, Singh R. Intractable glaucoma following intravitreal triamcinolone in central retinal vein occlusion. Am J Ophthalmol 2004; 137: 758-760.

16 Park $\mathrm{CH}$, Jaffe GJ, Fekrat S. Intravitreal triamcinolone acetonide in eyes with cystoid macular edema associated with central retinal vein occlusion. Am J Ophthalmol 2003; 136: 419-425.

17 Thompson JT. Cataract formation and other complications of intravitreal triamcinolone for macular edema. Am J Ophthalmol 2006; 141: 629-637.

18 Conway MD. The problem of pressure elevation associated with intravitreal triamcinolone. Br J Ophthalmol 2006; 90: 934-935.

19 Beer PM, Bakri SJ, Singh RJ, Liu W, Peters III GB, Miller M. Intraocular concentration and pharmacokinetics of triamcinolone acetonide after a single intravitreal injection. Ophthalmology 2003; 110: 681-686.

20 Jonas JB. Intraocular availability of triamcinolone acetonide after intravitreal injection. Am J Ophthalmol 2004; 137: 560-562.

21 Rahi JS, Edelsten C. The British Ophthalmological Surveillance Unit: the study of uncommon ophthalmic disorders made easier. Eye 1997; 11(Pt 6): 766-767. 